Concept Paper

\title{
Body-Mind Medicine Interventions in COVID-19 Place Confinement for Mental, Physical and Spiritual Wellbeing
}

\author{
Haywantee Ramkissoon 1, 2, 3, *
}

1. College of Business, Law, \& Social Sciences, Derby Business School, Kedleston Road, Derby, DE1 22GB, United Kingdom; E-Mail: $\underline{\text { H.Ramkissoon@derby.ac.uk }}$

2. School of Business \& Economics, Faculty of Biosciences, Fisheries \& Economics, UiT, The Arctic University of Norway, Norway

3. College of Business \& Economics, Johannesburg Business School, University of Johannesburg, South Africa

* Correspondence: Haywantee Ramkissoon; E-Mail: $\underline{\text { H.Ramkissoon@derby.ac.uk }}$

Academic Editors: Soo Liang Ooi and Dr Pak Sokcheon

Special Issue: Complementary, Traditional and Integrative Medicine in COVID-19

OBM Integrative and Complementary Medicine

2021, volume 6 , issue 2

doi:10.21926/obm.icm.2102016
Received: February 23, 2021

Accepted: April 09, 2021

Published: April 27, 2021

\begin{abstract}
The SARS-COV-2 virus has changed people's lives and caused significant public health issues. The lockdown implemented by several governments across the globe has raised serious concerns on mental and physical wellbeing. Doctors, nurses and other COVID-19 frontline workers being put under extreme pressure to attend to patients' health are being impacted by high stress levels which can result in burn-out and the inability to cope with the situation. This paper draws on multi-disciplinary research including complementary, traditional and integrative medicine, behavioral medicine, and social and environmental psychology to develop and propose a single integrative model of wellbeing encompassing dimensions of mental, physical and spiritual wellbeing in a pandemic context. The article discusses COVID19 place confinement as a context to deliver body-mind medicine interventions in this challenging time. The aim is to provide the required support to promote behavior change for better public health outcomes. A range of cognitive behavioral therapies including psycho-
\end{abstract}

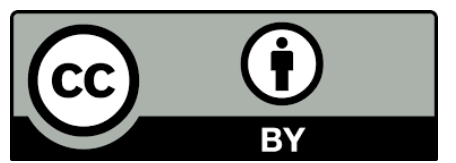

(C) 2021 by the author. This is an open access article distributed under the conditions of the Creative Commons by Attribution License, which permits unrestricted use, distribution, and reproduction in any medium or format, provided the original work is correctly cited. 
social, psycho-educational, relaxation, meditation and nature therapies are discussed. Promoting alternative forms of traditional, complementary and integrative medicine in the local, global communities are discussed as preventive and sustainable measures to improve public health and wellbeing aligning with Global Health and the United Nations Sustainable Development Goals. This has important implications for people's wellbeing and quality of life during and post the COVID-19 pandemic.

\section{Keywords}

COVID-19; mental wellbeing; physical wellbeing; spiritual wellbeing; body-mind interventions; place confinement; psycho-social therapy; nature therapy; psycho-education; meditation

\section{Introduction}

The SARS-COV-2 virus has changed people's lives and caused significant public health issues. The lockdown implemented by several governments across the globe raised serious concerns regarding mental and physical well-being. Doctors, nurses and other COVID-19 frontline workers are being put under extreme pressure to attend to patients' health. As a consequence, they are being impacted by high stress levels which can result in burn-out and the inability to cope with the situation. Staff of NHS in the UK have been experiencing fatigue; a general consensus has been reached among the general medical council and other co-actors for actions to be taken for their wellbeing [1].

Wellbeing has been well studied in literature. In the current pandemic, the concept has attracted significant interest from scholars, psychological practitioners and complementary, traditional and integrative medicine providers. Mental health professionals in complementary and integrative medicine are being encouraged to engage with local communities [2] to support their coping efforts and improve their wellbeing [3]. COVID-19 measures of social distancing need to respected (e.g. [4, 5]) encouraging the transition from face-to-face consultation to digital communication.

The operationalisation of wellbeing has been a great challenge for researchers with its complex aspects, definitions and dimensions creating a contradictory and confusing research base [6]. It is now however commonly agreed by most researchers that the concept of wellbeing is multidimensional in nature although the approaches differ (e.g., $[7,8])$. Wellbeing has been defined as "each time an individual meets a challenge, the system of challenges and resources comes into a state of imbalance, as the individual is forced to adapt his or her resources to meet this particular challenge [9]. Dodge and colleagues lend support to Kloep et al.'s [9] definition in their argument that wellbeing is about individuals being equipped with the physical, social, and psychological resources needed when faced with the respective challenges [10].

\subsection{Mental Wellbeing in COVID-19}

Measures of social distancing have been effective in managing significant pressures on healthcare globally, yet COVID-19 place confinement continues to have negative consequences on mental and physical wellbeing $[11,12]$. There is also increasing evidence suggesting that the COVID19 mutation continues to have a heavy toil on people's health and quality of life [13]. Place 
confinement has resulted in feelings of isolation, however social connections are still possible despite the fact that people are physically distanced. Scholars have identified interventions that could promote mental wellbeing encompassing psychological, social and emotional wellbeing in uncertain times such as crises and pandemics. Ramkissoon [14] argues that although people have to follow measures of social distancing, individuals can connect and form social bonds using online interactions and develop a sense of attachment to people and place. Special attention and assistance however will need to be devoted to those who are not familiar with information technology. Ramkissoon [5, 14] emphasized the urgent action needed from governments and other co-actors to promote residents' pro-social and pro-environmental behaviors while they are place confined and post the pandemic for mental health and wellbeing outcomes and better quality-oflife. Mental health interventions will also need to be provided to healthcare staff struggling with professional responsibilities in addition to their personal concerns on COVID-19 and its impact on their family life [15].

\subsection{Physical Wellbeing in COVID-19}

Physical mobility has been significantly decreased for many as a result of the COVID-19 place confinement rules across nations leading to other health issues. COVID-19 has brought closures of gyms, parks and other outdoor recreational settings posing a big challenge to those dependent on these environmental settings. It is important for people to look for innovative ways to maintain their physical wellbeing in the lock down period. Some degree of physical activity is required within the confined space due to limited access to other environmental settings. Physical activity has been reported to have a positive influence on individuals' physical well-being [16] through stress management, depression and anxiety reduction. Physical activity has been advocated to assist in recovery of some COVID-19 patients [17]. Complementary and traditional healthcare providers have been encouraging the practice of Pranayama (breathing exercises) in Ashtanga Yoga. Physical exercises in Ashtanga yoga can be very demanding which would usually need close supervision.

\subsection{COVID-19 and Spiritual Wellbeing}

In the current study, the author argues that in addition to the mental along with social and psychological and physical wellbeing, we also need to promote spiritual wellbeing. Spiritual wellbeing has been looked at in a number of studies (e.g., [18-20]). When people go through adverse situations, they may embrace spirituality. Spiritual wellbeing can contribute to people's overall quality of life [21].

\section{Conceptual Development}

\subsection{COVID-19 Place Confinement}

With COVID-19 and the mutant virus since the global health pandemic SARS-COV-2 which started in Wuhan, China in December 2019, people continue to be place confined in several countries of the world. Place confinement can be defined as physical immobility, where people are restricted to their place of residence, community, state, or country [14]. Appadurai [22] conceptualised place confinement as perceived threat to mobility. He argues that it is a feeling that natives of a place 
could have until they move to a new place where they can start feeling place confined again. We have generally studied people's behaviors when they are confined in hospitals, homes and prisons. There is now a resurgence of interest to understand human behavior in the COVID-19 pandemic place confinement context, and how the latter can provide a window of opportunity to contribute to better health outcomes [14]. There hasn't been much research with the exception of a few (e.g., $[14,23,24])$ on place confinement in epidemics. There continues to be increasing demand for governments and healthcare organizations to address the detrimental impacts on residents' mental and physical wellbeing. The health literature indicates that a lack of independence among people, especially when their physical activities are restricted may have a significant impact on their mental health (e.g., $[14,25,26])$. People being place confined during epidemics can generate emotional distress with continued isolation [14, 27]. Residents have demonstrated in some epidemic outbreaks that they may not readily adopt confinement behaviors in the first instance; however, they tend to so with increased self-awareness after being quarantined [24]. This can assist in curbing the spread of the epidemic.

As a consequence of the place confinement rules across nations, physical mobility has been significantly decreased for many residents globally leading to other health issues. Rajkumar [28] recent study shows that Asians have been reporting depressive and anxiety symptoms. Evidence in extant literature shows that the lack of physical activity among prisoners undergoing punishment in isolation has also been linked with anxiety and depression $[29,30]$. It is observed that elderly people being confined can become dependent on others who assist them with their routines e.g., eating, dressing [31]. Ramkissoon [5, 14] argues that some degree of physical activity remains important to promote physical and mental wellbeing. Recent studies are showing that the pandemic may be causing fear of infection, employment insecurity, uncertainty of the future among other issues to those in isolation [32-34]. During the pandemic, it is strongly recommended that people stay physically active within their home environment [14].

As we continue to witness the alarming implications of COVID-19 on global human health and impacts on healthcare systems, it has become apparent that we need to monitor more closely the psychosocial needs and provide the required support to our people. This calls for more forms of complementary, traditional and integrative medicine to lend support to clinical health. This next section discusses the different therapies that can be used in Mind-Body Medicine (MBM) to promote mental, physical and spiritual wellbeing of our people.

\subsection{Mind-Body Medicine (MBM) Interventions}

Mind -Body medicine (MBM) encompasses traditional healing systems used in ancient times with the modern biomedical treatment to provide an integrated model of health care [35]. MBM has been popular and gaining increased attention from scholars and health practitioners in the SARSCOV-2 pandemic as people continue to struggle with uncertainty anxieties. MBM includes cognitive behavioral techniques which combined with physical exercise, nature interventions, meditation and mindfulness, relaxation, psycho-social and psycho-education to promote people's health and wellbeing [36]. MBM shows the interaction between the brain, mind, body, and human behavior reducing individual and cellular stress, improving our immunity and promoting a general sense of wellbeing hence enhancing quality of life $[5,37]$. 


\subsubsection{Nature Therapy}

Contact with nature has been documented to have important psychological and physiological benefits [38-44] impacting positively on people's quality of life [45, 46]. An important point brought forward by researchers, and integrative medicine practitioners is that green space is playing a significant role assisting with COVID-19 recovery $[26,47,48]$. Walks in urban green spaces are being encouraged to promote health and wellbeing benefits during the lockdown [49]. Researchers are also promoting household behaviors that can assist in physical and mental wellbeing [5, 14]. A recent study by Corley et al. [50] explored the impact of green home space, in particular engagement with home gardening on elderly's physical and mental wellbeing. Ramkissoon, Smith, \& Weiler [51-53] and Ramkissoon, Mavondo, \& Uysal [37] also reported benefits of engagement with nature on overall quality of life. In her recent study, [5] Ramkissoon reflected at how engagement with nature can also bring pro-social behaviors among people in confinement and contribute to wellbeing and quality of life. Previous studies indicated that exposure to nature can enhance physical, psychological [44] and spiritual health with outcomes such as enhanced mood, happiness, higher self-esteem, vitality, and inner peace [54]. It is very important to start re-building the relationship between children and nature. More research is being demanded on exposure to nature and children's wellbeing [55]. This is increasingly important in the pandemic as children's routines have been highly disrupted with COVID-19 place confinement.

\subsubsection{Psycho-Social Therapy}

Psycho-social interventions can include social skills, occupational therapy, exercise therapy and psycho-education [56]. In the COVID-19 and post the pandemic, many patients may benefit from psychosocial therapy. This includes interventions designed to promote health and wellbeing outcomes. Psycho-social therapy can provide coping strategies to face the current impacts and after-effects of the pandemic. Examples of such interventions can include cognitive behavioral therapy, psycho-educational therapy, relaxation therapy, and meditation therapy. Medical doctors argue that there could be more suicidal tendencies necessitating the need for care from mental health professionals and possibly psychiatric treatment at the hospital [57]. Suicidal tendencies may be due to death of loved ones, bereavement, unemployment and economic crisis, inability to cope with existing medical conditions e.g., cancer, drugs, alcohol, domestic violence among other issues while being place confined during the COVID-19 pandemic. Complementary, traditional and integrative medicine providers can assist with the above by offering stress management and coping strategies. Examples of emotional distress can be from the news channels. The media relating SARSCOV-2 news can be emotionally draining to many, suggesting that patients' exposure to such sources needs to be monitored [57]. Researchers have also been suggesting the need for therapeutic landscapes and training of personnel to address patients' COVID-19 emotional distress $[33,49]$. Children feeling isolated from their school friends and peer groups also need to be supported through psycho-social therapy. This can possibly be effected online by behavioral psychologists and healthcare professionals. Clowning can be used to cheer children in hospitals [58] to increase their positive emotions.

\subsubsection{Psycho-Social Therapy and Telemedicine: Virtual Mind-Body Services}


One of the biggest challenges faced by health care providers has been the over-reliance on faceto-face consultations as opposed to digital health. In COVID-19 place confinement however, there has been an increased use of telemedicine in developed countries such as the USA. Unfortunately, these services are not yet available to people from various socio-economic backgrounds across the globe. There is an even more pressing need to offer virtual mind-body services to people in developing and poorer countries who may not be able to access their usual hospital in times of need. Integrative medicine providers could focus on online training materials for staff and online counselling for patients [59].

COVID-19 place confinement has provided an opportunity for digital empowerment of communities. While psychological, social and emotional empowerment may not necessarily be an outcome always, these serve to enhance people's quality of life $[5,60]$. In the COVID-19 era and post the pandemic, digital empowerment can contribute to people's overall quality-of-life by making care and personalised services more accessible through integrative telemedicine. An example which is being recommended to alternative medicine providers is that the public be provided with information about how to react to COVID-19 and the coping mechanisms to adopt in the most difficult circumstances [57].

\subsubsection{Psycho-Educational Therapy}

The aim of psycho-education therapy is to not only provide information on the disorder and its treatment, but also address social and family consequences of the disorder [61]. COVID-19 confinement pandemic encourages psycho-educational therapy. Ramkissoon [14] has recommended behavior change through psycho-education. She recommends adoption of pro-social and pro-environmental behaviors to better equip the global community with behaviors which would be psychologically restorative in both a confinement and post crisis context. Psycho-educational therapy in the COVID-19 place confinement can be used to promote behavior change for healthier lifestyles and positive psychosocial wellbeing impacts. Alternative and integrative medicine need to develop programs with health-promoting behaviors such as engaging in social and proenvironmental habits which are necessary to promote healthier lifestyles.

COVID 19 place confinement is driving a transformation in healthcare. Digital psycho-education therapy is being provided during the pandemic and is being further encouraged. Psycho-education is largely through social media channels providing educational coping strategies to alleviate the mental distress caused by the SARS-COV-2 virus $[5,14]$. Public health education about government initiatives to address COVID-19 challenges is also being provided online to reassure their people [62].

Psycho-education of healthcare leaders and front-liners assisting COVID-19 patients remains crucial. When exposed to continuous stressors caused by COVID-19, nurses and doctors and other front-liners can experience burnout. Burnout can be caused due to emotional exhaustion and hence a decreased sense of personal accomplishment [63]. COVID-19 front-liners are subject to suffering and death, institutional challenges, and changing technologies in transformation in health care. Psycho-education of staff is needed to promote their wellbeing. COVID-19 psycho-education interventions can include coping by promoting adaptation to the pandemic's various challenges. Psycho-education can help to promote stress reduction and resilience [64], hence minimizing the negative consequences of the COVID-19 perceived risk and threat [49]. The pandemic place confinement context provides an opportunity to cultivate meaning-based resilience, promoting pro- 
social interactions $[5,14,65,66]$, develop innovative techniques and expand coping options during and beyond the pandemic.

Psycho-education programs of self-care and coping need to also be developed and directed to people across communities. Some recent evidence (e.g., $[67,68])$ suggests that place confinement measures have been having negative consequences on patients' health demanding for more pathways to alleviate the stress on COVID-19 patients. These can be designed to explain the significance of self-care in and beyond the pandemic, understanding the coping mechanisms and designing and following a wellness plan. Psycho-education is highly recommended in such challenging times as the SARS-COV-2 pandemic for the mental wellbeing of healthcare leaders and professionals, and patients [57] not only in the developed world but also across all nations.

Psycho-education needs to focus primarily on empowerment of communities as COVID-19 place confinement can further aggravate traumatic experiences leading to post-traumatic syndromes. Crisis communication messaging can be used to emphasize the importance of social bonds [69, 70] which can assist in alleviating loneliness and sufferings $[14,71]$. Social bonding plays an important role on promoting quality of life [37]. Researchers and health advisors working on COVID-19 are recommending talking to neighbours where permissible while maintaining social distancing [14]. A few studies (e.g., [72]) have also been examining COVID-19 patients' perceived stress and effectiveness of online psycho-educational tools. Social networks over the internet are proving to be effective.

Psycho-education interventions also need to be implemented across communities across different social groups to examine vaccine availability and acceptability. This has important implications for behavior change and people's mental health and wellbeing $[14,73]$.

\subsubsection{Meditation Therapy}

Meditation can be about the seeking of deeper truth with our attention focussed on particular aspects of inner or outer experience $[74,75]$. It has been and is still increasingly being used in alternative medicine as a health care intervention across different cultural contexts [76]. Meditation has been taught essentially to quieten the mind and the ongoing mental chatter by focusing and chanting a mantra, showing kindness and compassion, and mindful breathing [76]. Others have employed the mindfulness technique in meditation which relies on simply acknowledging our thoughts, emotions and feelings without judging ourselves [77, 78]. A meta-analysis of 163 studies concluded that mindfulness meditation is associated with greater wellbeing [79].

Meditation is being evidenced to be an important technique to be practiced and promoted in the current COVID-19 and post the pandemic. Mindfulness meditation has been shown to have a positive impact on female teachers' mental health and wellbeing in the SARS-COV-2 outbreak in Italy [80]. Hanna and Pidgeon [81] and Behan [76] argue that of the many different forms of meditation and mindfulness, what have been evidenced in showing improvements in depression, panic, anxiety and pain is mindfulness-based stress reduction (MBSR). Having MBSR as a low-cost method to complement medical treatment in COVID-19 and post the pandemic is being of particular interest to healthcare professionals and in alternative medicine $[57,76]$. Meditation is also being applied in traditional Indian and Chinese medicine [82-84] for COVID-19 stress alleviation [85]. Mindfulness was associated with a reduction in depressive symptoms and elevated positive 
emotions [82]. This lends support to mindfulness being an effective coping strategy in uncertain and stressful circumstances [86].

Meditation is being shown to bring mental health benefits through internet-based interventions during COVID 19 place confinement. Complementary medicine practitioners have been providing meditation sessions taught via online courses. Scholars have been looking at the effectiveness of using a meditation app in reducing anxiety and improving well-being during the pandemic (e.g., [87]) demanding for more conclusive findings in this interesting study area. Mindfulness has also been recommended for children and adolescents for stress management and eating disorders [88]. It can be provided as supportive treatment to children and adolescents suffering from COVID-19 behavior disorders due to place confinement.

\subsubsection{Relaxation Therapy}

Relaxation techniques need to be highly encouraged in the COVID 19 era and post the pandemic. Relaxation in complementary and integrative medicine is used to reduce stress and includes meditation as well as muscle relaxation. The practice includes the use of oils and scents, medicated water, aryuvedic herbs, and the practice of Yoga [84, 89]. The pandemic's disruption to people's routines in addition to problems of loneliness can bring other health risks such as sleep deprivation. Sleep plays a fundamental role in regulating our emotions, and sleep disturbance impacts on our emotional wellbeing.

COVID-19 place confinement could have people engaging in lesser activities which can impact on sleep negatively [90]. There have been a range of recommendations including cognitive behavioral therapy for insomnia (CBT-I) that is recommended for sleep deprivation in crisis situations [91, 92]. Relaxation techniques can be delivered by psychological counsellors over the internet. Online relaxation has also been recommended to dementia patients during COVID-19 [93].

COVID-19 place confinement has also evidenced a deterioration of work-life balance for many as a result of having to spend more time with other family members in a common space [90]. Online relaxation techniques can provide a break from the tensions and 'worry-time' to foster one's psychological wellbeing.

\subsection{The Proposed Conceptual Framework}

Place confinement in COVID-19 provides a window of opportunity for complementary, traditional and integrative medicine healthcare practitioners. This will however require behavioral change at all levels. It is important to design interventions and identify the barriers and enablers that will guide the choice of these interventions for the providers and the public's wellbeing during and post the SARS-COV-2 pandemic [94]. The designed interventions will also need to be drawn from theory and be relevant to people's environmental, economic and social settings. This paper draws on multidisciplinary research streams including traditional health, and complementary and integrative medicine, behavioral and environmental psychology, and sociology (e.g., [14, 15, 84]). A single integrative model of wellbeing is developed and proposed using the COVID-19 place confinement as the context. The associations between the constructs under investigation are depicted by arrows in the conceptual framework. 


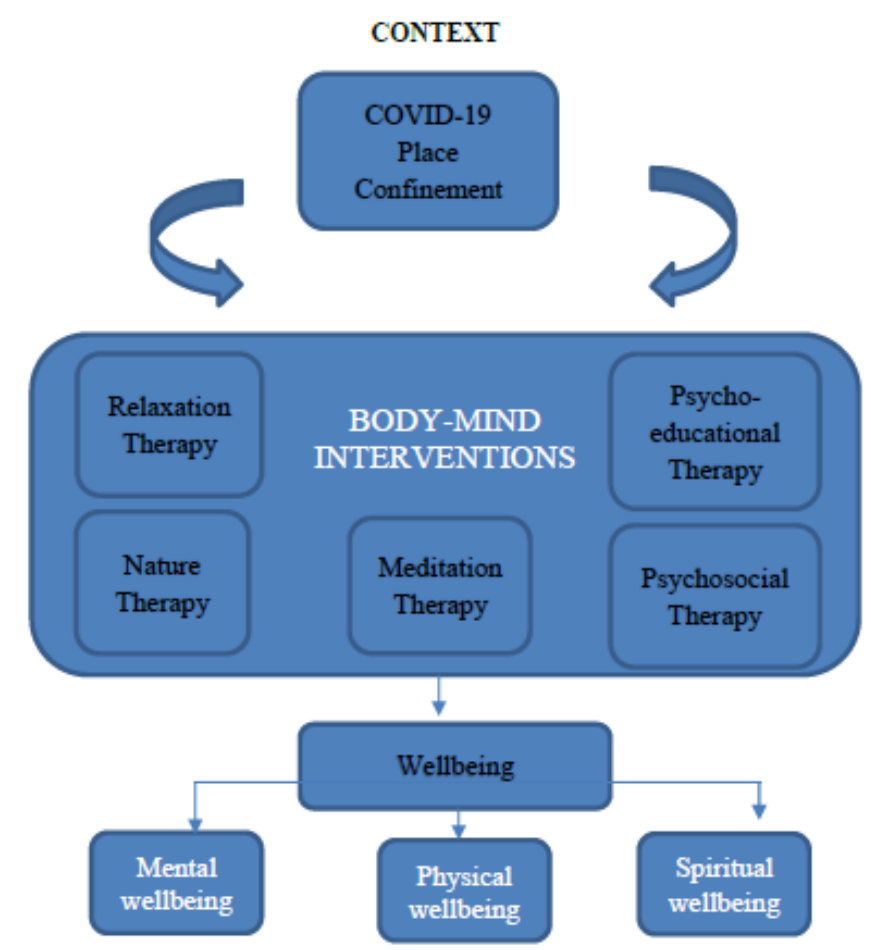

Figure 1 Conceptual framework.

\section{Conclusion}

This paper discusses how integrative medicine interventions need to be increasingly adopted to assist traditional medicine. The aim is to provide the required support to promote lifestyle change and better public health outcomes. Promoting alternative forms of integrative medicine in the local, and global communities are discussed as preventive and sustainable measures to improve public health and wellbeing aligning with Global Health and the United Nation Sustainable Development Goals (SDGs). This has important implications for people's wellbeing and quality of life during and post the COVID-19 pandemic.

This article draws on psycho-social behavioral, health and environmental psychology literature and explores the COVID-19 place confinement context to assist and promote alternative forms of health care such as body-mind medicine. It discusses the opportunities that the pandemic brought forward in supporting clinical practice which has been greatly impacted by the home and community confinement. As a result, the need for more psycho-social services are being recognised and demanded by medical doctors to assist patients. A range of cognitive behavioral therapies including psycho-social, psycho-educational, relaxation, meditation therapies and nature therapies are discussed. Provision of complementary and alternative medicine in the pandemic is very important and strongly recommended $[84,95,96]$. This can be achieved through collective efforts by stakeholders in the community, businesses, healthcare providers, governments and the local people $[5,14]$. New pathways in healthcare such as integrative medicine in healthcare using telemedicine [62] are discussed. A multi-stakeholder engagement approach is recommended to promote wellbeing outcomes across communities [94; 97-101] and align with the UN Sustainable Development Goals (SDGs) in promoting good health and global wellbeing $[5,14]$. It will be 
important to continue the interventions in the post pandemic context until people see the effectiveness of the proposed strategies [102]. The local community is an important stakeholder in designing better healthcare. Governments and clinical and complementary and integrative healthcare professionals need to exercise thoughtful and deliberate planning of how to engage with the public in this uncertain time of the pandemic. This will require continued engagement strategies.

\section{Author Contributions}

HR did all the research work in this study.

\section{Competing Interests}

The author has declared that no competing interests exist.

\section{References}

1. Unadkat S, Farquhar M. Doctors' wellbeing: Self-care during the COVID-19 pandemic. BMJ. 2020; 368: $m 1150$.

2. Shankar A, Dubey A, Saini D, Prasad CP. Role of complementary and alternative medicine in prevention and treatment of COVID-19: An overhyped hope. Chin J Integr Med. 2020; 26: 565.

3. Zacher $\mathrm{H}$, Rudolph $\mathrm{CW}$. Individual differences and changes in subjective wellbeing during the early stages of the COVID-19 pandemic. Am Psychol. 2020; 76: 50-62.

4. Honey-Rosés J, Anguelovski I, Chireh VK, Daher C, Konijnendijk van den Bosch C, Litt JS, et al. The impact of COVID-19 on public space: An early review of the emerging questions-design, perceptions and inequities. Cities \& Health; 2020; 1-17.

5. Ramkissoon H. Perceived social impacts of tourism and quality-of-life: A new conceptual model. J Sustainable Tourism. 2020; 1-7.

6. Pollard EL, Lee PD. Child well-being: A systematic review of the literature. Soc Indic Res. 2003; 61: 59-78.

7. Diener E. Subjective well-being. In: The science of well-being. New York: Spring; 2009. pp.11-58.

8. Michaelson J, Abdallah S, Steuer N, Thompson S, Marks N. National accounts of well-being: Bringing real wealth onto the balance sheet. London: New Economics Foundation; 2009.

9. Kloep M, Hendry L, Saunders D. A new perspective on human development. Conference of the International Journal of Arts and Sciences; 2009 June.

10. Dodge R, Daly AP, Huyton J, Sanders LD. The challenge of defining wellbeing. Int J Wellbeing. 2012; 2: 222-235.

11. Douglas M, Katikireddi SV, Taulbut M, McKee M, McCartney G. Mitigating the wider health effects of covid-19 pandemic response. Bmj. 2020; 27: 369.

12. Holmes EA, O'Connor RC, Perry VH, Tracey I, Wessely S, Arseneault L, et al. Multidisciplinary research priorities for the COVID-19 pandemic: A call for action for mental health science. Lancet Psychiatry. 2020; 7: 547-560.

13. Desai S, Rashmi S, Rane A, Dharavath B, Sawant A, Dutt A. An integrated approach to determine the abundance, mutation rate and phylogeny of the SARS-CoV-2 genome. Brief Bioinformatics. 2021; 22: 1065-1075. 
14. Ramkissoon H. COVID-19 Place confinement, pro-social, pro-environmental behaviors, and residents' wellbeing: A new conceptual framework. Front Psychol. 2020; 11: 2248.

15. Van Bavel JJ, Baicker K, Boggio PS, Capraro V, Cichocka A, Cikara M, et al. Using social and behavioural science to support COVID-19 pandemic response. Nat Hum Behav. 2020; 4: 460471.

16. Lesser IA, Nienhuis CP. The impact of COVID-19 on physical activity behavior and well-being of Canadians. Int J Environ Res Public Health. 2020; 17: 3899.

17. Dwyer MJ, Pasini M, De Dominicis S, Righi E. Physical activity: Benefits and challenges during the COVID-19 pandemic. Scand J Med Sci Sports. 2020; 30: 1291.

18. Captari LE, Hook JN, Aten JD, Davis EB, Tisdale TC. Embodied spirituality following disaster: Exploring intersections of religious and place attachment in resilience and meaning-making. The Psychology of Religion and Place. 2019; 49-79.

19. Hassan, A, Ramkissoon, H. Augmented reality application for visitor experiences in naturebased tourism. CABI. 2021: 118-130.

20. Bai M, Lazenby M. A systematic review of associations between spiritual well-being and quality of life at the scale and factor levels in studies among patients with cancer. J Palliat Med. 2015; 18: 286-298.

21. Ramkissoon $\mathrm{H}$, Uysal M. Authenticity as a value co-creator of tourism experiences. Creating experience value in tourism. 2014: 113-124.

22. Appadurai A. Putting hierarchy in its place. Cult Anthropol. 1988; 3: 36-49.

23. Orset C. People's perception and cost-effectiveness of home confinement during an influenza pandemic: Evidence from the French case. Eur J Health Econ. 2018; 19: 1335-1350.

24. Zhu G, Chen G, Fu X. Effects of active links on epidemic transmission over social networks. Physica A. 2017; 468: 614-621.

25. Haney C. Mental health issues in long-term solitary and "supermax" confinement. Crime Delinq. 2003; 49: 124-156.

26. Metzner JL, Fellner J. Solitary confinement and mental illness in US prisons: A challenge for medical ethics. Health Hum Rights Chang World. 2013; 1: 316-323.

27. Aronson J. Elderly people's accounts of home care rationing: Missing voices in long-term care policy debates. Ageing Soc. 2002; 22: 399-418.

28. Rajkumar RP. COVID-19 and mental health: A review of the existing literature. Asian J Psychiatr. 2020; 52: 102066.

29. Arrigo BA, Bullock JL. The psychological effects of solitary confinement on prisoners in supermax units: Reviewing what we know and recommending what should change. Int J Offender Ther Comp Criminol. 2008; 52: 622-640.

30. Mears DP, Reisig MD. The theory and practice of supermax prisons. Punishm Soc. 2006; 8: 3357.

31. Doumit J, Nasser R. Quality of life and wellbeing of the elderly in Lebanese nursing homes. Int J Health Care Qual Assur. 2010; 23: 72-93.

32. Salem IE, Elkhwesky Z, Ramkissoon H. A content analysis for government's and hotels' response to COVID-19 pandemic in Egypt. Tourism Hospitality Res. 2021; 14673584211002614.

33. Duan L, Zhu G. Psychological interventions for people affected by the COVID-19 epidemic. Lancet Psychiatry. 2020; 7: 300-302.

34. Fernandez-Rio J, Cecchini JA, Mendez-Gimenez A, Carriedo A. Mental well-being profiles and 
physical activity in times of social isolation by the COVID-19: A latent class analysis. Int J Sport Exercise Psychol. 2021; 28: 1-15.

35. Barrows KA, Jacobs BP. Mind-body medicine: An introduction and review of the literature. Med Clin North Am. 2002; 86: 11-31.

36. Seifert G, Jeitler M, Stange R, Michalsen A, Cramer H, Brinkhaus B, et al. The relevance of complementary and integrative medicine in the COVID-19 pandemic: A qualitative review of the literature. Front Med. 2020; 7: 946.

37. Ramkissoon $\mathrm{H}$, Mavondo F, Uysal M. Social involvement and park citizenship as moderators for quality-of-life in a national park. J Sustain Tour. 2018; 26: 341-361.

38. Akhshik A, Rezapouraghdam $H$, Ramkissoon $H$. Industrialization of nature in the time of complexity unawareness: The case of Chitgar Lake, Iran. J Hosp Tour Res. 2020; 1096348020964949.

39. Rezapouraghdam $H$, Akhshik A, Ramkissoon $H$. Application of machine learning to predict visitors' green behavior in marine protected areas: Evidence from Cyprus. J Sustain Tour. 2021; 29: 1-25.

40. Marselle MR, Warber SL, Irvine KN. Growing resilience through interaction with nature: Can group walks in nature buffer the effects of stressful life events on mental health? Int J Environ Res Public Health. 2019; 16: 986.

41. Ramkissoon $H$, Smith LD, Kneebone S. Visitor satisfaction and place attachment in national parks. Tourism Anal. 2014; 19: 287-300

42. Ramkissoon $\mathrm{H}$, Mavondo FT. The satisfaction-place attachment relationship: Potential mediators and moderators. J Bus Res. 2015; 68: 2593-2602.

43. Ramkissoon $\mathrm{H}$, Mavondo FT. Proenvironmental behavior: Critical link between satisfaction and place attachment in Australia and Canada. Tour Anal. 2017; 22: 59-73.

44. Townsend M, Henderson-Wilson C, Ramkissoon H, Werasuriya R. Therapeutic landscapes, restorative environments, place attachment, and well-being. Oxford textbook of nature and public health. The role of nature in improving the health of a population. 2018; 57-62.

45. Ramkissoon H. Place satisfaction, place attachment and quality of life: Development of a conceptual framework for island destinations. In: Sustainable Island Tourism: Competitiveness and Quality of Life. Wallingford: CABI. 2016; 106-116.

46. Ramkissoon $H$, Weiler B, Smith LD. Place attachment and pro-environmental behaviour in national parks: The development of a conceptual framework. J Sustain Tour. 2012; 20: 257-276.

47. Ahmadpoor N, Shahab S. Realising the value of greenspace: A planners' perspective on the COVID-19 pandemic. Town Plann Rev. 2021; 92: 49-56.

48. Ferrini F, Gori A. Cities after COVID-19: How trees and green infrastructures can help shaping a sustainable future. Ri-Vista. 2020; rv-8553.

49. Majeed S, Ramkissoon $\mathrm{H}$. Health, wellness, and place attachment during and post health pandemics. Front Psychol. 2020; 11: 573220.

50. Corley J, Okely JA, Taylor AM, Page D, Welstead M, Skarabela B, et al. Home garden use during COVID-19: Associations with physical and mental wellbeing in older adults. J Environ Psychol. 2021; 73: 101545.

51. Ramkissoon H, Smith LD, Weiler B. Relationships between place attachment, place satisfaction and pro-environmental behaviour in an Australian national park. J Sustain Tour. 2013; 21: 434457. 
52. Ramkissoon $\mathrm{H}$, Smith LD, Weiler B. Testing the dimensionality of place attachment and its relationships with place satisfaction and pro-environmental behaviours: A structural equation modelling approach. Tour Manag. 2013; 36: 552-566.

53. Ramkissoon $\mathrm{H}$, Weiler $\mathrm{B}$, Smith LD. Place attachment, place satisfaction and pro-environmental behaviour: A comparative assessment of multiple regression and structural equation modelling. J Policy Res Tour Leisure Events. 2013; 5: 215-232.

54. Hassan A, Ramkissoon H. Potentials of tourism products and services in Bangladesh. New York: Routledge; 2020.

55. Kabisch $\mathrm{N}$, van den Bosch $\mathrm{M}$, Lafortezza $\mathrm{R}$. The health benefits of nature-based solutions to urbanization challenges for children and the elderly-A systematic review. Environ Res. 2017; 159: 362-373.

56. Gühne U, Weinmann S, Arnold K, Becker T, Riedel-Heller SG. S3 guideline on psychosocial therapies in severe mental illness: Evidence and recommendations. Eur Arch Psychiatry Clin Neurosci. 2015; 265: 173-188.

57. Pfefferbaum B, North CS. Mental health and the Covid-19 pandemic. N Engl J Med. 2020; 383: 510-512.

58. Dionigi A, Dionigi A, Dionigi A. Healthcare clowning: Use of specific complementary and alternative medicine for hospitalized children. OBM Integr Complement Med. 2018; 3: 1-12.

59. Chen Q, Liang M, Li Y, Guo J, Fei D, Wang L, et al. Mental health care for medical staff in China during the COVID-19 outbreak. Lancet Psychiatry. 2020; 7: e15-e16.

60. Aleshinloye KD, Woosnam KM, Tasci AD, Ramkissoon H. Antecedents and outcomes of resident empowerment through tourism. J Travel Res. 2021; 17: 0047287521990437.

61. de Azevedo Cardoso T, Mondin TC, Reyes AN, Zeni CP, de Mattos Souza LD, da Silva RA, et al. Biological rhythm and bipolar disorder: Twelve-month follow-up of a randomized clinical trial. J Nerv Ment Dis. 2015; 203: 792-797.

62. Ting DS, Carin L, Dzau V, Wong TY. Digital technology and COVID-19. Nat Med. 2020; 26: 459461.

63. Maslach C, Jackson SE, Leiter MP. MBI: Maslach burnout inventory. Palo Alto: Consulting psychologists press; 1996.

64. Fergus S, Zimmerman MA. Adolescent resilience: A framework for understanding healthy development in the face of risk. Annu Rev Public Health. 2005; 26: 399-419.

65. Kniffin KM, Narayanan J, Anseel F, Antonakis J, Ashford SP, Bakker, AB, et al. COVID-19 and the workplace: Implications, issues, and insights for future research and action. Am Psychol. 2021; 76: 63.

66. Kravits K, McAllister-Black R, Grant M, Kirk C. Self-care strategies for nurses: A psychoeducational intervention for stress reduction and the prevention of burnout. Appl Nurs Res. 2010; 23: 130-138.

67. Bo HX, Li W, Yang Y, Wang Y, Zhang Q, Cheung T, et al. Posttraumatic stress symptoms and attitude toward crisis mental health services among clinically stable patients with COVID-19 in China. Psychol Med. 2020; 50: 1-2.

68. Devita M, Bordignon A, Sergi G, Coin A. The psychological and cognitive impact of Covid-19 on individuals with neurocognitive impairments: Research topics and remote intervention proposals. Aging Clin Exp Res. 2021; 33: 733-736.

69. Brooke J, Jackson D. Older people and COVID-19: Isolation, risk and ageism. 2020; 29: 2044- 
2046.

70. Public Health England. Guidance for the public on the mental health and wellbeing aspects of Coronavirus (COVID-19) [Internet]. London: Public Health England; 2020. Available from: https://www.gov.uk/government/publications/covid-19-guidance-for-the-public-on-mentalhealth-and-wellbeing/guidance-for-the-public-on-the-mental-health-and-wellbeing-aspectsof-coronavirus-covid-19\#older-people.

71. Banerjee D. The COVID-19 outbreak: Crucial role the psychiatrists can play. Asian J Psychiatr. 2020; 50: 102014.

72. Shaygan M, Yazdani Z, Valibeygi A. The effect of online multimedia psychoeducational interventions on the resilience and perceived stress of hospitalized patients with COVID-19: A pilot cluster randomized parallel-controlled trial. BMC Psychiatry. 2021; 21: 1-12.

73. Alves GS, Casali ME, Veras AB, Carrilho CG, Bruno Costa E, Rodrigues VM, et al. A systematic review of home-setting psychoeducation interventions for behavioral changes in dementia: Some lessons for the COVID-19 pandemic and post-pandemic assistance. Front Psychiatry. 2020; 11: 1028.

74. Goleman DJ, Schwartz GE. Meditation as an intervention in stress reactivity. J Consult Clin Psychol. 1976; 44: 456-466.

75. Shapiro SL, Schwartz GE, Bonner G. Effects of mindfulness-based stress reduction on medical and premedical students. J Behav Med. 1998; 21: 581-599.

76. Behan $\mathrm{C}$. The benefits of meditation and mindfulness practices during times of crisis such as COVID-19. Ir J Psychol Med. 2020; 37: 256-258.

77. Miller JJ, Fletcher K, Kabat-Zinn J. Three-year follow-up and clinical implications of a mindfulness meditation-based stress reduction intervention in the treatment of anxiety disorders. Gen Hosp Psychiatry. 1995; 17: 192-200.

78. Wolsko PM, Eisenberg DM, Davis RB, Phillips RS. Use of mind-body medical therapies. J Gen Intern Med. 2004; 19: 43-50.

79. Sedlmeier P, Eberth J, Schwarz M, Zimmermann D, Haarig F, Jaeger S, et al. The psychological effects of meditation: A meta-analysis. Psychol Bull. 2012; 138: 1139-1171.

80. Matiz A, Fabbro F, Paschetto A, Cantone D, Paolone AR, Crescentini C. Positive impact of mindfulness meditation on mental health of female teachers during the COVID-19 outbreak in Italy. Int J Environ Res Public Health. 2020; 17: 6450.

81. Hanna A, Pidgeon AM. Leveraging mindfulness to build resilience and professional quality of life in human service professionals. OBM Integr Complement Med. 2018; 3: 007.

82. Sweeny K, Rankin K, Cheng X, Hou L, Long F, Meng Y, et al. Flow in the time of COVID-19: Findings from China. PloS ONE. 2020; 15: e0242043.

83. Thirthalli J, Zhou L, Kumar K, Gao J, Vaid H, Liu H, et al. Traditional, complementary, and alternative medicine approaches to mental health care and psychological wellbeing in India and China. Lancet Psychiatry. 2016; 3: 660-672.

84. Tillu G, Chaturvedi S, Chopra A, Patwardhan B. Public health approach of ayurveda and yoga for COVID-19 prophylaxis. J Altern Complement Med. 2020; 26: 360-364.

85. Liang F, Litscher G. COVID-19 (Coronavirus Disease-19): Traditional chinese medicine including acupuncture for alleviation-A report from Wuhan, Hubei Province in China. OBM Integr Complement Med. 2020; 5: 1-4. 
86. Sweeny K, Howell JL. Bracing later and coping better: Benefits of mindfulness during a stressful waiting period. Pers Soc Psychol Bull. 2017; 43: 1399-1414.

87. O'Donnell KT, Dunbar M, Speelman DL. Effectiveness of using a meditation app in reducing anxiety and improving well-being during the COVID-19 pandemic: A structured summary of a study protocol for a randomized controlled trial. Trials. 2020; 21: 1-2.

88. Semple R, Burke C. State of the research: Physical and mental health benefits of mindfulnessbased interventions for children and adolescents. OBM Integr Complement Med. 2019; 4: 31.

89. Sahni PS, Singh K, Sharma N, Garg R. Yoga an effective strategy for self-management of stressrelated problems and wellbeing during COVID19 lockdown: A cross-sectional study. PloS ONE. 2021; 16: e0245214.

90. Altena E, Baglioni C, Espie CA, Ellis J, Gavriloff D, Holzinger B, et al. Dealing with sleep problems during home confinement due to the COVID-19 outbreak: Practical recommendations from a task force of the European CBT-I Academy. J Sleep Res. 2020; 29: e13052.

91. Boullin P, Ellwood C, Ellis JG. Group vs. individual treatment for acute insomnia: A pilot study evaluating a "One-Shot" treatment strategy. Brain Sci. 2017; 7: 1.

92. Randall C, Nowakowski S, Ellis JG. Managing acute insomnia in prison: Evaluation of a "one-shot" cognitive behavioral therapy for insomnia (CBT-I) intervention. Behav Sleep Med. 2019; 17: 827836.

93. Wang H, Li T, Barbarino P, Gauthier S, Brodaty H, Molinuevo JL, Xie H, et al. Dementia care during COVID-19. Lancet. 2020; 395: 1190-1191.

94. Ramkissoon, H. Tourism and behaviour change. In: Encyclopedia of Tourism Management \& Marketing. 2nd ed. Cheltenham: Edward Elgar.

95. Ling CQ. Traditional Chinese medicine is a resource for drug discovery against 2019 novel coronavirus (SARS-CoV-2). J Integr Med. 2020; 18: 87.

96. Hunter J, Arentz S, Goldenberg J, Yang G, Beardsley J, Lee MS, et al. Choose your shortcuts wisely: COVID-19 rapid reviews of traditional, complementary and integrative medicine. Integr Med Res. 2020; 9: 100484.

97. Nunkoo R, Ramkissoon H. Developing a community support model for tourism. Ann Tour Res. 2011; 38: 964-988.

98. Nunkoo R, Ramkissoon H. Power, trust, social exchange and community support. Ann Tour Res. 2012; 39: 997-1023.

99. Nunkoo R, Ramkissoon H, Gursoy D. Public trust in tourism institutions. Ann Tour Res. 2012; 39 : 1538-1564.

100. Nunkoo R, Ramkissoon, H. Stakeholders' views of enclave tourism: A grounded theory approach. J Hospitality Tourism Res. 2016; 40: 557-558.

101. Nunkoo R, Smith SL, Ramkissoon H. Residents' attitudes to tourism: A longitudinal study of 140 articles from 1984 to 2010. J Sustain Tour. 2013; 21: 5-25.

102. Ramkissoon H. Review of: Interventions to increase personal protective behaviours to limit the spread of respiratory viruses: A rapid evidence review and meta-analysis. Qeios. 2021; HHXEOF. 
OBM Integrative and Complementary Medicine 2021; 6(2), doi:10.21926/obm.icm.2102016

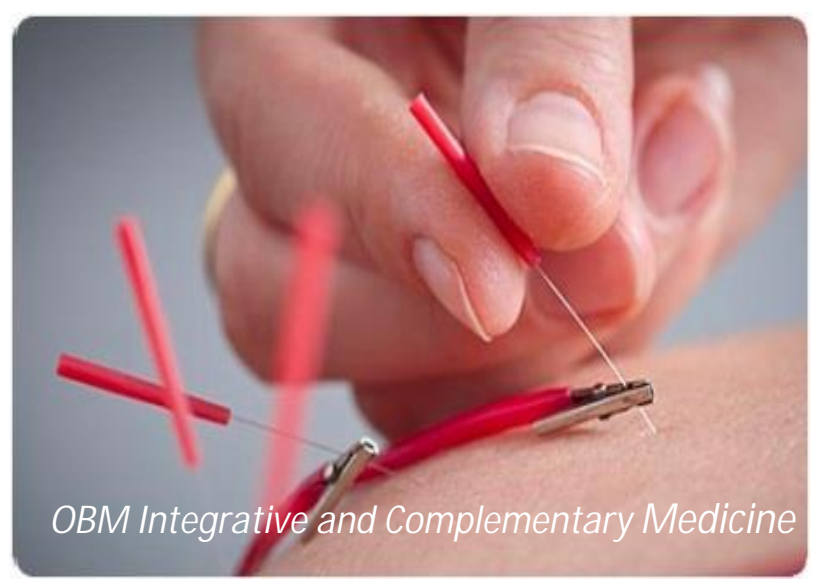

Enjoy OBM Integrative and Complementary Medicine by:

1. Submitting a manuscript

2. Joining in volunteer reviewer bank

3. Joining Editorial Board

4. Guest editing a special issue

For more details, please visit:

http://www.lidsen.com/journals/icm 